\title{
Uma reflexão sobre as práticas pedagógicas do professor de Metodologia de Pesquisa
}

\section{no Ensino Superior}

\author{
Reflection on the pedagogical practices of the professor of Research Methodology in Higher
}

Education

Una reflexión sobre las prácticas pedagógicas del profesor de Metodología de la Investigación en Educación Superior

Recebido: 09/09/2021 | Revisado: 15/09/2021 | Aceito: 19/09/2021 | Publicado: 19/09/2021

Gislaine Hanke

ORCID: https://orcid.org/0000-0002-1073-8784 Brilhar Formação Educação, Brasil E-mail: gihanke@gmail.com

Susel Taís Coelho Soares

ORCID: https://orcid.org/0000-0003-4681-968X Instituto Federal de Mato Grosso, Brasil E-mail: suseltais@gmail.com

Joseany Sebastiana Silva Moreira

ORCID: https://orcid.org/0000-0002-1473-8386 Secretaria de Estado de Educação SEDUC, Brasil

E-mail: joseanymoreira2011@ hotmail.com

Katherine Iasmim Carneiro

ORCID: https://orcid.org/0000-0001-5525-4719

Secretaria de Estado de Educação SEDUC, Brasil

E-mail: kilimadesouza@hotmail.com

Patrícia Miranda

ORCID: https://orcid.org/0000-0001-9859-4836

Faculdade Santa Marcelina, Brasil

E-mail: patmirandabio@gmail.com

Alexandre Horácio Couto Bittencourt

ORCID: https://orcid.org/0000-0002-3838-1609 Centro Universitário FAMINAS, Brasil

E-mail: bittencourt.alex@gmail.com

Marcela Marques

ORCID: https://orcid.org/0000-0001-5537-0461

Secretaria de Estado de Educação SEDUC, Brasil

E-mail: m.marquesbio@gmail.com

\begin{abstract}
Resumo
Um dos maiores desafios para o docente do Ensino Superior é manter-se autorreflexivo quanto às práticas pedagógicas e o papel da formação continuada, reciclando e incorporando conhecimentos e saberes, competências e habilidades, bem como alinhá-las aos avanços tecnológicos e científicos. Através de revisão bibliográfica pudemos notar que a postura profissional por meio das práticas pedagógicas, o domínio dos saberes e o exercício da atualização tecnológica e conhecimento científico influenciam positivamente no processo ensino-aprendizagem, tornando-o mais agradável e proveitoso. Amparados no exposto, o objetivo da pesquisa é elucidar como a associação dos saberes e competências do docente aos métodos e práticas pedagógicas do Ensino Superior contribuem para tornar a disciplina de Metodologia de Pesquisa em uma disciplina atrativa aos discentes.

Palavras-chave: Competência do docente; Metodologia de pesquisa; Ensino superior.

\section{Abstract}

One of the biggest challenges for Higher Education teachers is to remain self-reflective about pedagogical practices and the role of Continuous Education, recycling and incorporating knowledges, skills and abilities, aligning them with technological and scientific advances. Through a literature review, we could notice that the professional attitude through pedagogical practices, the mastery of knowledge, the exercise of technological updating and scientific knowledge positively influence the teaching-learning process, making it more pleasant and profitable. Based on the above, the aim of this research is to elucidate how the association of the teacher's knowledge and skills with the pedagogical methods and practices of Higher Education contribute to turning the discipline of Metodologia de Pesquisa (Research Methodology) into an attractive discipline for students.
\end{abstract}

Keywords: Teacher's capability; Research methodology; Higher education. 


\begin{abstract}
Resumen
Uno de los mayores desafíos para los docentes de Educación Superior es mantenerse auto-reflexivos sobre las prácticas pedagógicas y el rol de la educación continua, reciclando e incorporando conocimientos y conocimientos, habilidades y destrezas, además de alinearlos con los avances tecnológicos y científicos. A través de una revisión de la literatura, pudimos notar que la actitud profesional a través de las prácticas pedagógicas, el dominio del conocimiento y el ejercicio de la actualización tecnológica y del conocimiento científico influyen positivamente en el proceso de enseñanza-aprendizaje, haciéndolo más ameno y rentable. Con base en lo anterior, el objetivo de la investigación es dilucidar cómo la asociación de conocimientos y habilidades del docente a los métodos y prácticas pedagógicas de la Educación Superior contribuyen a hacer de la disciplina de Metodología de la Investigación una disciplina atractiva para los estudiantes.
\end{abstract}

Palabras clave: Competencia docente; Metodología de investigación; Enseñanza superior.

\title{
1. Introdução
}

No contexto atual da docência no Ensino Superior reciclar-se é primordial não apenas para manter-se atuante na profissão e garantir um lugar no mercado de trabalho, mas para reciclar conhecimentos, saberes, competências e habilidades. Por este motivo levantamos o seguinte questionamento: Como associar os saberes e competências do docente aos métodos e práticas pedagógicas do Ensino Superior no exercício de sua profissão? Quando se fala em saberes e competências do docente do Ensino Superior, alguns profissionais se delimitam as aptidões que o indivíduo desenvolve no decorrer de sua vida acadêmica, seja ela no exercício da profissão ou como nas competências como aluno, entretanto no ambiente educacional isso vai muito além.

Para conseguir que no exercício da docência os discentes sejam comprometidos, o docente do Ensino Superior tem que estar em constante busca de novas tendências e práticas pedagógicas para ministrar aulas, visto que estamos diante de um processo de ampliação do campo da docência universitária, onde a docência requer formação profissional para seu exercício, como: conhecimentos específicos, habilidades vinculadas à atividade docente e dedicação para ser tornar um diferencial dos demais.

Martins et al (2018) trazem as contribuições de Schön, que cunhou o termo "professor reflexivo", onde o autor apregoa a proposta de nova epistemológica: a reflexão-na-ação, considerando a construção do conhecimento mediante a reflexividade e a valorização da prática profissional.

Por meio da pesquisa bibliográfica com cunho qualitativo (Bogdan \& Biklen, 1982; Silva, 2013) pretende-se demonstrar e trazer à reflexão como a associação dos saberes e competências do docente aos métodos e práticas pedagógicas do Ensino Superior contribuem para tornar a disciplina de Metodologia de Pesquisa numa disciplina atrativa aos discentes do Ensino Superior.

\section{Saberes Docentes e Relevância da Docência do Ensino Superior}

A docência no Ensino Superior dissemina sua relevância, ao longo dos anos, deixando evidente que o profissional que a exerce tende a estar munido de um conjunto de saberes, saberes esses disciplinares, adquiridos na academia associados às práticas cotidianas vivenciadas por esse profissional para o bom exercício de sua profissão.

Os saberes do profissional docente são concretizados através do seu processo de vida, de sua formação e atuação profissional, como menciona Tardif (2014) quando fala que o saber dos professores está relacionado a uma situação de trabalho envolvendo tanto alunos quanto colegas de trabalho, um saber ancorado numa tarefa complexa referindo ao processo de ensinar, num determinado local (a sala de aula, a escola), enraizado numa instituição e numa sociedade.

Nesta mesma linha de pensamento Zabalza (2004) atribui três funções aos professores universitários: o ensino (docência), a pesquisa e a administração em diversos setores da instituição e, cabe acrescentar a função de orientação 
acadêmica: monografias, dissertações e teses. Novas funções agregam-se a estas, tornando mais complexo o exercício profissional, referenciado por Vargas (2017) como uma gama de conhecimentos aliada à construção do conhecimento junto aos alunos. Em suma, os saberes dos professores são plurais!

Entender o conjunto necessário para desempenhar o trabalho docente, com a epistemologia, a pedagogia, os saberes técnicos e a experiência profissional, torna-se fator determinante para uma formação pessoal e profissional de qualidade. Visto que a prática docente não é apenas um objeto de saber, mas uma atividade que mobiliza os diversos saberes que podemos chamá-los de pedagógicos.

Sendo o exercício da docência uma profissão, com natureza de um processo mediador entre sujeitos relativamente diferentes, professores e alunos, confrontando a conquista do conhecimento, Pimenta \& Anastasiou (2010) trazem a importância de conhecer a realidade dos acadêmicos e da sociedade onde estão inseridos, bem como as condições disponibilizadas pela instituição de ensino.

Sabedor desde cenário, Maurice Tardif (2014) em sua obra "Saberes Docentes e Formação Profissional" destaca e classifica os diferentes tipos de saberes como veremos no quadro abaixo:

Quadro 1 - Classificação dos saberes docentes.

\begin{tabular}{|c|c|}
\hline SABER & DEFINIÇÃO \\
\hline $\begin{array}{l}\text { Saberes da } \\
\text { Formação } \\
\text { Profissional }\end{array}$ & $\begin{array}{l}\text { Conjunto de saberes que, baseados nas ciências e na erudição, são transmitidos aos professores durante o processo de } \\
\text { formação inicial e/ou continuada. Também se constituem o conjunto dos saberes da formação profissional os } \\
\text { conhecimentos pedagógicos relacionados às técnicas e métodos de ensino (saber-fazer), legitimados cientificamente e } \\
\text { igualmente transmitidos aos professores ao longo do seu processo de formação, como exemplo a pedagogia chamada de } \\
\text { "ativa". }\end{array}$ \\
\hline $\begin{array}{c}\text { Saberes } \\
\text { Disciplinares }\end{array}$ & $\begin{array}{l}\text { São os saberes reconhecidos e identificados como pertencentes aos diferentes campos do conhecimento (linguagem, } \\
\text { ciências exatas, ciências humanas, ciências biológicas, etc.). Esses saberes, produzidos e acumulados pela sociedade ao } \\
\text { longo da história da humanidade, são administrados pela comunidade científica e o acesso a eles deve ser possibilitado } \\
\text { por meio das instituições educacionais. }\end{array}$ \\
\hline $\begin{array}{c}\text { Saberes } \\
\text { Curriculares }\end{array}$ & $\begin{array}{l}\text { São conhecimentos relacionados à forma como as instituições educacionais fazem a gestão dos conhecimentos } \\
\text { socialmente produzidos e que devem ser transmitidos aos estudantes (saberes disciplinares). Apresentam-se, } \\
\text { concretamente, sob a forma de programas escolares (objetivos, conteúdos, métodos) que os professores devem aprender } \\
\text { e aplicar. }\end{array}$ \\
\hline $\begin{array}{c}\text { Saberes } \\
\text { Experienciais }\end{array}$ & $\begin{array}{l}\text { São os saberes que resultam do próprio exercício da atividade profissional dos professores. Esses saberes são } \\
\text { produzidos pelos docentes por meio da vivência de situações específicas relacionadas ao espaço da escola e às relações } \\
\text { estabelecidas com alunos e colegas de profissão. Nesse sentido, "incorporam-se à experiência individual e coletiva sob } \\
\text { a forma de habitus e de habilidades, de saber-fazer e de saber ser". }\end{array}$ \\
\hline
\end{tabular}

Fonte: Tardif (2002, pp. 36-38).

Observando o quadro acima podemos ultimar que a docência no seu exercício demanda os 4 pilares dos saberes, os saberes próprios do docente, que aplicados se multiplicam em sua profissão, visto que baseia-se no saber-fazer, nos diferentes campos de conhecimento produzidos ao longo da jornada como discente, na sua interiorização dos programas escolares bem como a relação de trabalho e de sua formação.

Assim, Bireaud (1995) chama de isomorfismo quando o aluno se torna um professor e exerce as práticas pedagógicas do jeito que aprendeu na sua formação com seus formadores; o professor universitário aprende a sê-lo, em grande parte, mediante os modelos que o formaram.

A docência implica em desafios e exigências, como Zabalza (2004) retrata que para o desenvolvimento da docência são necessários conhecimentos específicos para exercê-la adequadamente, ou, no mínimo, é necessária a aquisição dos conhecimentos e das habilidades vinculados à atividade docente para melhorar sua qualidade, para tanto, a formação inicial e continuada é fundamental para valorização do exercício da docência e consequentemente da qualidade do ensino. Freire (1997, 
p.110) faz um alerta ao afirmar que "Ensinar exige compreender que a educação é uma forma de intervenção no mundo". Ensinar é perseguir um fim, é empregar meios para atingir certas finalidades para quando chegar ao final contextualizar na prática que os discentes absorveram e esses conseguem retransmitir esse conhecimento adquirido.

Deste modo o art. 13 da Lei 9394/96 estabelece as seguintes incumbências para os professores:

- Participar da elaboração do projeto pedagógico;

- Elaborar e cumprir o plano de trabalho;

- Zelar pela aprendizagem dos alunos;

- Estabelecer estratégias de recuperação para alunos de menor rendimento;

- Ministrar os dias letivos e horas-aula estabelecidos;

- Participar integralmente dos períodos dedicados ao planejamento, à avaliação e ao desenvolvimento profissional.

Para cumprir essas finalidades pedagógicas propostas pela Lei inerentes ao seu trabalho, o docente deve tomar certas decisões na manutenção da ordem em sala de aula e no ensinamento do conteúdo, nos métodos e aplicação de avaliação, para que o processo de ensino e a aprendizagem sejam os melhores possíveis. Do mesmo modo, os discentes necessitam estar em processo evolutivo na sua formação, se reciclando sempre através de cursos, palestras, almejando novos desafios acadêmicos, para que seus conhecimentos técnicos e científicos se ampliem e sejam acrescentados.

Diante deste cenário não há dúvida de que estamos perante um processo de ampliação do campo da docência universitária, e que se faz indispensável ao professor apreender os conhecimentos teóricos necessários para identificar a sua atuação pedagógica, para ter clara a sua intencionalidade quanto ao aluno que irá formar. Ainda nesse processo ensino e aprendizagem, o professor deve refletir sobre quais são os paradigmas que fundamentam sua ação docente, sendo evidente que as práticas pedagógicas tendem estar ligadas aos processos tecnológicos e bem alinhadas aos saberes do docente, o que veremos mais a fundo no tópico a seguir.

\section{Práticas Pedagógicas da Docência do Ensino Superior na Disciplina de Metodologia de Pesquisa}

A postura dos alunos na sala de aula é o desafio a ser enfrentado pelo docente, sendo necessário agrupar conhecimentos adquiridos na sua formação, seus próprios conhecimentos inerentes da sua prática de vida com as novas tendências e práticas pedagógicas.

Da Fernandes e Silva (2017) em seu artigo "Práticas Pedagógicas para o Ensino Superior", pontuam perfeitamente essa definição ao dizer que a prática pedagógica requer entre outros recursos, a estratégia de trabalhar com a mudança de paradigma, definida por Cortella (2016) como a "visão do outro lado", isto é, o professor mostra o outro lado, indicando exemplos e maneiras de fazer e modelos.

É comum se ouvir hoje em dia que os alunos atuais, são diferentes dos alunos de antigamente, então, porque sabendo disso, os professores continuam dando aula do mesmo jeito de antes? Diante do aluno contemporâneo, tanto a base educativa, quanto a preparação do aluno graduando requer do processo educativo atualização, qualidade compatível com a modernização social e econômica. (Fernandes \& Silva, 2017, p.364).

Quando o acesso à informação era mais limitado, fazia sentido privilegiar o acesso à transmissão de informações pelos professores utilizando-se de metodologias tradicionais (Valente, 2005). A partir da ampliação de acesso à internet e a divulgação de diversos cursos e materiais, pode-se aprender em qualquer lugar, a qualquer hora e com inúmeras pessoas. Isso é complexo, necessário e um pouco assustador, porque não temos modelos prévios bem sucedidos para aprender de forma flexível numa sociedade altamente conectada. 
Em face às práticas pedagógicas no Ensino Superior na posição ensino-aprendizagem, tem ganhado espaço e força a andragogia (do grego: andros = adulto e gogos = educar), "a arte e a ciência de ajudar adultos a aprender" (Carvalho et al., 2010, p.4).

Segundo Hamze (2008) a andragogia é um caminho educacional capaz de compreender o adulto, de modo que pode ser considerada não só uma teoria, mas também um método de ensino, uma vez que este reflete num somatório de trocas de conhecimentos entre o facilitador do conhecimento e o estudante adulto e suas experiências de vida. Pinto (2007, p. -) assevera que "A andragogia é o método de fundamental importância no processo de educação do adulto, por se tratar de pessoa já dotada de uma consciência formada, com hábitos de vida e situações de trabalho que não podem ser arbitrariamente modificados.".

Sendo atualmente, a andragogia, uma alternativa à pedagogia tradicional para jovens e adultos, uma vez que a educação é centrada no estudante (Deaquino, 2007).

O docente em seu campo de trabalho necessita cada vez mais estar munido de conhecimentos e técnicas para conseguir se posicionar em frente a sala de aula, direcionando bem esses alunos que já tem um certo grau de conhecimento, evidenciando que a sala de aula é o ambiente propício para troca de conhecimento entre professores e alunos.

A aprendizagem requer que o sujeito tenha desejo de aprender, e que pode ser evidenciado pela necessidade de superar desafios e obstáculos ou de responder uma dúvida.

Os exemplos dos grandes chefes de cozinha devem ser absorvidos por educadores no âmbito da sala de aula. É preciso significar o ensino, apresentar alternativas diferenciadas, buscar caminhos que despertem a curiosidade, a reflexão e a imaginação dos aprendentes. É preciso variar sempre, pois todo dia, a mesma coisa torna o ensino enfadonho, sem atração alguma e nada significativo. Isto indica que, o ensino deve ser conduzido no entendimento de que a aula se apresenta "como momento e espaço privilegiado de encontro de ações - não deve ser dada nem assistida, mas construída, feita pela ação conjunta de professores e alunos." (Domingues, 2016 p.28).

Considerando que aconteça esse aprendizado que Domingues (2016) aponta através da prática, o profissional docente pode construir seu olhar sobre o aprender "sempre". Ter a humildade no entendimento dessa necessidade para o desempenho profissional que, através do relacionamento com os demais colegas vai permitir a troca de informações e experiências que irão contribuir para o crescimento pessoal e profissional de todos.

Assim, só se consegue difundir conhecimento na busca do mesmo, e pensar a aula no Ensino Superior não significa chegar à sala de aula e ministrar um conteúdo. É possível trabalhar esse conteúdo buscando estimular nos estudantes o gosto pela pesquisa, pela descoberta de novos saberes, bem como, do quão importante é para a vida acadêmica e profissional a compreensão do conteúdo e a construção de novos conhecimentos. "[...] o ensino, fenômeno complexo, enquanto prática social realizada por seres humanos com seres humanos é modificada pela ação e relação desses sujeitos, que, por sua vez, são modificados nesse processo." (Pimenta \& Anastasiou, 2010 p. 1).

$\mathrm{O}$ interesse pela pesquisa se aprimora quando o docente demonstra em sua aula, meio pelo qual deixa a mesma mais atrativa e marcante para o aluno, meios esse que hoje no ambiente acadêmicos conhecemos como Tecnologias Digitais da Informação e da Comunicação (TDICs), que é o uso da tecnologia, que necessariamente não substituem outras formas de aprender e ensinar, mas sua contribuição está na melhoria da qualidade desse ensino aprendizagem, em uma maior aproximação docente-discente fazendo com que se produzam conhecimentos a partir dessa maior interação.

O professor precisa estar ciente e preparado para atuar nesta nova realidade que se descortinou na sociedade. Preparado não só na compreensão e uso das tecnologias, mas principalmente nas diferentes metodologias que devem ser utilizadas em sala de aula, bem como fora dela, no relacionamento social com seus alunos. (Cerutti, 2015).

No Ensino Superior pode-se ver e sentir essa atuação com maior facilidade; tele aulas, videoconferências com 
professores até mesmo do outro lado do mundo. Essas novas tecnologias vieram para ficar, e o educador como tal precisa estar preparado para um ensino que ligue saber ao fazer (Vargas, 2017).

Atualmente, um novo momento acontece que reabre a questão do uso ou não de tecnologias no processo educacional. Trata-se do desenvolvimento das Tecnologias de Informação e Comunicação (TICs), com o uso da internet e do computador, com o acesso imediato e em tempo real às informações, ao conhecimento, às experiências e projetos inovadores, com a possibilidade de socialização imediata das pesquisas, com o surgimento, a multiplicação e a diversidade dos aparelhos eletrônicos e games digitais. (Masetto, 2012, p.143).

Diante das possibilidades relacionadas com as diversas tecnologias disponíveis, como auxílio para o docente, compete a esse selecionar o que lhe proporciona segurança e se encaixa com a proposta do conteúdo de sua disciplina para utilização na aula. Visto que o docente da disciplina de Metodologia de Pesquisa precisa mergulhar nesse oceano das tecnologias para trazer para sala de aula o melhor e mais atual conteúdo.

\section{Tecnologias, Educação e Preparação do Professor de Metodologia de Pesquisa}

O professor de Metodologia de Pesquisa, como educador, deve assumir a responsabilidade ética de ser um multiplicador de novas ideias, possibilitando qualidade e condições de desenvolvimento de seus alunos, assumindo sua tarefa pessoal de expandir a própria consciência, com auxílio das ferramentas tecnológicas, que se torna necessário como mediação da aprendizagem para que haja uma melhoria no processo ensino-aprendizagem.

A sociedade atual vivencia hoje o surgimento de novas formas de estabelecimento de contato e circulação de informações. Neste sentido, as TIC exercem grande influência já que permeiam os diversos espaços e fazem parte da vida de inúmeras pessoas que diminuem a distância e buscam conectar-se, utilizando o ciberespaço. (Tavares \& Gomes, 2018, p. 61).

Por este motivo, não podemos deixar de inserir nesse cenário educacional, o contexto de tecnologias inseridas na vida e profissão do docente, tornando-se necessário esclarecer sobre a necessidade dos docentes interiorizar que a tecnologia está aí à disposição como ferramenta didática para a realização do trabalho docente criando novas oportunidades para que o ensino e a aprendizagem de qualidade estejam presentes na construção de saberes. Carvalho; Bastos \& Kruger (2000, p. 15) salientam que "A educação em suas relações com a Tecnologia pressupõe uma rediscussão de seus fundamentos em termos de desenvolvimento curricular e formação de professores, assim como a exploração de novas formas de incrementar o processo ensino-aprendizagem.".

No livro "Informática e Formação de Professores" Almeida (2000, p.7) diz que "Nós educadores temos que nos preparar e preparar nossos alunos para enfrentar as exigências dessa nova tecnologia e de todas que estão à sua volta $-\mathrm{a}$ tv, $\mathrm{o}$ vídeo, a telefonia celular, internet. A informática aplicada à educação tem dimensões mais profundas que não aparecem à primeira vista.".

Kenski (2012, p. 64) em seu livro "Didática, o ensino e suas relações" explica os sucessivos avanços da tecnologia no decorrer das décadas, enfatizando as diferentes formas de se explicar um determinado tópico apresentado na teoria e na prática. A autora situa as relações entre os avanços da tecnologia e as mudanças da forma de utilizá-las na sociedade em diferentes épocas, o avanço tecnológico acelera as formas de aquisição do conhecimento, e pelo da tecnologia o professor pode se tornar imprescindível ou descartável. Desde os tempos mais remotos o homem utiliza inovações técnicas e tecnológicas de acordo com a sua época. As transformações nestas áreas gradativamente possibilitam o avanço e o desenvolvimento dos povos. $\mathrm{O}$ domínio de novas informações e ferramentas ampliam os vieses do aprendizado e geram riquezas.

O docente deve ter em mente que as Tecnologias da Informação e Comunicação (TIC) não objetivam eliminar o uso de técnicas convencionais de ensino. Elas devem ser incorporadas ao processo educacional já existente. Entende-se que as competências que os alunos devem alcançar na sua aprendizagem podem ser melhoradas ou facilitadas por meio de métodos 
pedagógicos que utilizam novas TICs. No entanto, quando se pretende utilizar qualquer tecnologia no processo ensinoaprendizagem, o professor deve ter em conta a sua integração em uma perspectiva pedagógica para que esse uso seja o mais adequado possível. (Lobo \& Maia, 2015, p.20).

Já no artigo práticas pedagógicas para o Ensino Superior, Fernandes e Silva (2017) afirmam que o aluno atual já chega na escola com uma significativa carga de informação e informatizado, portanto, sua atitude é mais questionadora, tanto o aluno da educação básica quanto o do Ensino Superior. O aluno desta geração, não tem limites para utilização da tecnologia e a utiliza a todo tempo, dentro e fora da sala de aula. O mundo está mais dinâmico e em alguns aspectos a educação requer uma reflexão para uma revisão adaptativa.

Em se tratando deste acesso à informação que os discentes têm, Lobo e Maia (2015) pontuam um quesito muito importante do papel do docente em relação ao ensino e aprendizagem de suas turmas: estimular o raciocínio lógico destes discentes em relação aos conteúdos acessados, a partir de recursos que os fazem questionar sobre o assunto e os façam otimizar sua compreensão. Kenski (2001, p. 15) aduz que "As tecnologias digitais permitem aos professores trabalhar na fronteira do conhecimento que pretende ensinar. Mais ainda, possibilitam que eles e seus alunos possam ir além e inovar, gerar informações novas não apenas no conteúdo, mas também na forma como são viabilizadas nos espaços das redes.".

Sabedores destes recursos tecnológicos disponíveis os discentes do Ensino Superior tendem a cada dia ampliar o campo de atuação e ministração das aulas de metodologia de pesquisa, visto que se esses recursos forem acessíveis aos discentes, a tendência é que a produção acadêmica se amplie e se desenvolva com mais qualidade.

Segundo Teixeira (2010), para que se alcance uma educação de qualidade esta deve estar atrelada ao conhecimento. Dessa maneira, será possível a construção do conhecimento voltado para uma educação comprometida e, realmente, construtiva.

E assim, na educação do século XXI, o professor atuará como mediador da aprendizagem, tendo em vista que a informação não garante conhecimento nem aprendizagem, uma vez que a informação precisa ser reelaborada, interpretada, analisada, criticada e até mesmo desconstruída. Desta forma, o professor deve ter competências tecnológicas (saber usar softwares e redes sociais) e pedagógicas (fazer leitura crítica das informações que estão difusas na rede). (Tavares \& Gomes, 2018, p. 68).

Por isso o discente ao aplicar a disciplina assume a responsabilidade de abrir os olhos dos discentes para o valor da pesquisa, pois tanto docente, quanto o estudante fará uso da pesquisa para aprimorar, pôr em prática e construir conhecimento de maneira significativa durante o seu processo de ensino aprendizagem. Mais uma vez constata-se a importância das tecnologias no processo de ensino aprendizagem.

Com tudo, o docente além do domínio competente para promover ensino de qualidade, precisa ter um razoável conhecimento das possibilidades e do uso do computador, das redes e demais suportes midiáticos em variadas e diferenciadas atividades de aprendizagem para aplicar a disciplina de Metodologia de Pesquisa com eficiência. Isso ocorre quando o discente coloca em uso as práticas pedagógicas observamos no tópico anterior.

No entanto, ministrar a aula de Metodologia de Pesquisa já vista pelos alunos como uma disciplina, teórica, chata e sem importância no âmbito da graduação/pós-graduação? Quais métodos e práticas pedagógicas utilizar para que os discentes vejam que é uma disciplina necessária para completar sua carga horária, bem como ferramenta que abre um leque de oportunidades tanto no ambiente acadêmico como pessoal e profissional? Esta é a proposta do próximo tópico, demonstrar como a associação dos saberes e competências do docente com os métodos e práticas pedagógicas podem tornar a disciplina Metodologia de Pesquisa numa disciplina atraente aos discentes do Ensino Superior. 


\section{Metodologia de Pesquisa no Ensino Superior: uma Disciplina Atraente}

O discente, ao ingressar na vida acadêmica no Ensino Superior, já tem uma bagagem de quem veio de um Ensino Fundamental e Médio acompanhando as novas metodologias e práticas de ensino abordadas no meio escolar. É de se esperar, mesmo que superficialmente, que esse aluno já tenha noções de como devem ser estruturados seus trabalhos no âmbito acadêmico, seguindo a norma culta e científica. Pois a Metodologia de Pesquisa, além de ser uma disciplina obrigatória nos cursos superiores, é fundamental para todo percurso da vida acadêmica dos alunos que cursam o Ensino Superior no Brasil.

Apesar disso, um dos maiores desafios para o discente é o domínio das metodologias para desenvolvimento do trabalho científico, pois no decorrer trajetória acadêmica os projetos de pesquisa, artigos, dissertações e teses serão parte de suas atividades acadêmicas, portanto, faz-se necessário que o aluno trilhe os caminhos do saber, fazendo uso de instrumentos científicos para alcançar seus objetivos na vida acadêmica.

A produção do conhecimento científico exige algumas regras/métodos imprescindíveis para o seu sucesso e isso a Metodologia de Pesquisa explica detalhadamente. Um trabalho acadêmico não surge rápido ou facilmente, por isso, não deve ser escrito de qualquer forma.

De acordo com Libâneo (2001) a disciplina de Metodologia da Pesquisa tem como primeiro objetivo o de resgatar em nossos alunos a capacidade de pensar. Pensar significa passar de um nível espontâneo, primeiro e imediato a um nível reflexivo, segundo mediado. O pensamento pensa o próprio pensamento, para melhor captá-lo, distinguir a verdade do erro. Aprende-se a pensar à medida que se souber fazer perguntas sobre o que se pensa.

Logo, a disciplina de Metodologia de Pesquisa, além de nortear o passo a passo para organizar esse pensamento, consiste no estudo de métodos e técnicas para organizar de uma forma estrutural o que se deseja escrever. É importante destacar que essa escrita deve ser feita de forma clara e acadêmica.

Com essa afirmação chegamos ao ponto chave para definição do objetivo da disciplina Metodologia de Pesquisa, que é o caminho para se chegar ao fim, ou seja, os passos que o discente precisa percorrer para desenvolver um trabalho científico, para alcançar os seus objetivos propostos.

Tartuce (2006) aponta que a metodologia científica aborda o método e a ciência. Método (do grego methodos; significa "caminho para chegar a um fim") é, portanto, o caminho em direção a um objetivo; metodologia é o estudo do método, ou seja, é o corpo de regras e procedimentos estabelecidos para realizar uma pesquisa; científica deriva de ciência, a qual compreende o conjunto de conhecimentos precisos e metodicamente ordenados em relação a determinado domínio do saber. Metodologia científica é o estudo sistemático e lógico dos métodos empregados nas ciências, seus fundamentos, sua validade e sua relação com as teorias científicas.

De acordo com o especialista Galliano (1986, p. 12), "ao analisar um fato, o conhecimento científico não apenas trata de explicá-lo, mas também busca descobrir suas relações com outros fatos e explicá-los.”.

Percebe-se perfeitamente nos discentes, quando estão estudando a disciplina de Metodologia de Pesquisa, o que Galliano (1986) discorre acima, que os acadêmicos encontram muitas dificuldades para cumprir as exigências das universidades, provavelmente, em decorrência de uma formação deficiente na formação anterior. Fato esse que é refletido quando precisam desenvolver um trabalho científico. Muitos não conhecem ou não dominam as normas mais elementares para a elaboração de um texto científico, tais como: desenvolvimento e estrutura do trabalho, padrões de redação, procedimentos para se fazer pesquisas bibliográficas, seleção e organização da leitura das obras, construção de citações diretas e indiretas, bem como sobre o propósito de incluí-las no corpo do próprio texto.

Entra em cena a parte indicada por Masetto (2012), que espera-se do professor: 
Que tenha conhecimento de várias técnicas ou estratégias, bem como o domínio do uso destas para poder utilizá-las em aula; Que desenvolva capacidade de adaptação das diversas técnicas, modificando-as naquilo que for necessário para que possam ser usadas com aproveitamento pelos alunos individualmente ou em grupos; Que, pelo conhecimento e domínio prático de muitas técnicas e por sua capacidade de adaptação das técnicas existentes, se torne capaz de criar novas técnicas que melhor respondam às necessidades de seus alunos. Afinal, técnicas são instrumentos e como tais podem ser criadas por aqueles que vão usá-las. (Masetto, 2012, p. 103).

Para Vasconcelos (2005) o professor precisa ter sensibilidade para selecionar aquilo que é de interesse do aluno, daí a importância do planejamento e dos objetivos. Cabe a ele motivar e instigar a curiosidade e o interesse do aluno quanto aos conteúdos abordados. Compete ao professor e ao aluno entender o porquê e para quê.

Vale mencionar que, referente à proposta do ensino superior em relação ao desenvolvimento do discente, a Lei 9394/96 - Lei de Diretrizes e Bases da Educação descreve:

Art. 43. A educação superior tem por finalidade:

I - estimular a criação cultural e o desenvolvimento do espírito científico e do pensamento reflexivo;

II - formar diplomados nas diferentes áreas de conhecimento, aptos para a inserção em setores profissionais e para a participação no desenvolvimento da sociedade brasileira, e colaborar na sua formação contínua;

III - incentivar o trabalho de pesquisa e investigação científica, visando ao desenvolvimento da ciência e da tecnologia e da criação e difusão da cultura, e, desse modo, desenvolver o entendimento do homem e do meio em que vive;

IV - promover a divulgação de conhecimentos culturais, científicos e técnicos que constituem patrimônio da humanidade e comunicar o saber através do ensino, de publicações ou de outras formas de comunicação;

$\mathrm{V}$ - suscitar o desejo permanente de aperfeiçoamento cultural e profissional e possibilitar a correspondente concretização, integrando os conhecimentos que vão sendo adquiridos numa estrutura intelectual sistematizadora do conhecimento de cada geração;

VI - estimular o conhecimento dos problemas do mundo presente, em particular os nacionais e regionais, prestar serviços especializados à comunidade e estabelecer com esta uma relação de reciprocidade;

VII - promover a extensão, aberta à participação da população, visando à difusão das conquistas e benefícios resultantes da criação cultural e da pesquisa científica e tecnológica geradas na instituição. (Brasil,1996).

Mediante a amplitude deste artigo da Lei, observa-se que o desenvolvimento do sistema de Ensino Superior torna-se cada vez mais complexo e as instituições tendem a exigir cada dia mais dos profissionais habilitados ao exercício da docência o domínio da disciplina de Metodologia de Pesquisa para que esses continuem a contribuir com mais qualidade para o processo de aprendizagem dos discentes.

Logo, o professor precisa transmitir ao aluno, que está cursando o nível superior, que a disciplina de Metodologia Científica não é um conteúdo a ser decorado pelo acadêmico ou para ser verificado num dia de prova; trata-se de fornecer aos acadêmicos um instrumento indispensável para que sejam capazes de atingir os objetivos da academia, que são o estudo e a pesquisa em qualquer área do conhecimento.

Tartuce (2006) define a metodologia como método de estudo se torna primordial que o docente e o discente estejam cientes que a Metodologia de Pesquisa acompanhará o estudante durante toda sua jornada acadêmica. Durante o curso de graduação ela auxiliará na execução de pesquisas e em como apresentar os resultados dessas pesquisas e dominar os princípios norteadores da MP para adquirir/produzir conhecimento, numa postura ativa no processo ensino/aprendizagem.

Sendo assim, com bases nos autores, deve-se considerar o quanto é importante se ter o domínio da prática da pesquisa, cientificando que os estudantes que realizam a pesquisa científica na Universidade, estão em sua maioria, mais preparados para o mercado de trabalho, adquirem amadurecimento profissional e se destacam entre outros estudantes na hora da tomada de decisão.

Dentro dessa concepção, percebe-se também que esta disciplina é essencial para o desenvolvimento de um trabalho científico, pois é nessa que os acadêmicos aprenderão como se faz trabalhos, artigos, projetos, monografias, teses e afins, em 
que o papel do docente neste momento é o de orientar, ensinar, trabalhar de forma clara e objetiva com seu aluno, tendo uma linguagem que pode mudar a conduta do estudante frente às etapas que surgirão.

Conscientes disso, os discentes submeterão suas produções às normatizações dos trabalhos acadêmicos regulados pelo órgão responsável: Associação Brasileira de Normas Técnicas - ABTN. Fundada em 28 de setembro de 1940, a ABNT é responsável pela elaboração das Normas Brasileiras (ABNT NBR) que regulamentam os processos técnicos para a escrita e também as normatizações dos trabalhos acadêmicos exigidos pelas faculdades, por isso ela apresenta tantas regras, detalhes, indicações rígidas para digitação e formatação do texto, que, em certos momentos, parecem reprimir a liberdade do aluno em pensar e escrever, mas pelo contrário, elas dão suporte para que o conteúdo escrito por esse aluno seja bem visto e analisado de forma diferente pelas instituições de Ensino Superior.

A metodologia, porém, objetiva bem mais do que levar o aluno a elaborar projetos, a desenvolver um trabalho monográfico ou um artigo científico como requisito final e conclusivo de um curso acadêmico, mas também levar o aluno a comunicar-se de forma correta, inteligível, demonstrando um pensamento estruturado, plausível e convincente, através de regras que facilitam e estimulam à prática da leitura, da análise e interpretação de textos e consequentemente a formação de juízo de valor, crítica ou apreciação com argumentação plausível e coerente, visto que uma das exigências para o ingresso no mestrado, além das provas, é a apresentação de um projeto de pesquisa de um determinado tema vinculado às linhas de pesquisa dos programas, devendo este, estar bem estruturado contendo o problema da pesquisa ou o que chamamos também de pergunta norteadora, objetivo geral e específicos, justificativa, metodologia, resultados esperados, fundamentação teórica e cronograma.

Atualmente a necessidade de prosseguir os estudos além da graduação, como o objetivo de aprimorar o conhecimento ou concluir o processo de formação educacional, leva os graduandos a iniciarem estudos em nível de pós-graduação, cursos com natureza lato sensu e stricto sensu. O que há em vista nesses cursos é o desenvolvimento da capacidade criadora e do juízo crítico do aluno, para levá-lo a exercer a atividade de pesquisa científica. Desta forma, os trabalhos monográficos desenvolvidos nesses cursos caracterizam-se pelo domínio do assunto, pela capacidade de sistematização e de pesquisa do criador. (Prodanov, 2013 p.168).

Dessa forma, a metodologia vai além da descrição dos procedimentos (métodos e técnicas a serem utilizados na pesquisa), indicando a escolha teórica realizada pelo pesquisador para abordar o objeto de estudo. Sendo o método científico um traço característico da ciência, constituindo-se em instrumento básico que ordena, inicialmente, o pensamento em sistemas e traça os procedimentos do cientista ao longo do caminho até atingir objetivo científico preestabelecido. (Prodanov, 2013 p. 169).

Demo (2006, p.87) nos apresenta o mentor primordial que se torna o estimulador dessa grande busca em aprimorar os conhecimentos ao dizer que "Assim, estar motivados na construção de saberes e na busca de uma formação cidadã é essencial para professor e aluno.”. O professor de verdade motiva o aluno a dominar a escrita e a leitura como instrumentação formal e política do processo de formação do sujeito social emancipado.

A boa redação científica e alto desempenho durante a escrita do trabalho de conclusão de curso, dissertação, tese ou artigos científicos para publicação em periódicos, somente serão alcançados se o aluno fizer uso consecutivo da leitura, crítica e reflexiva, de outros artigos e trabalhos científicos. Assim, este processo irá proporcionar que o estudante se familiarize com os termos específicos de cada área de conhecimento e se torne mais confiante e preparado para desempenhar a difícil missão de redigir seu trabalho final. (Praça, 2015).

Então, para que os discentes consigam desenvolver sua vida acadêmica com mais facilidade, eles têm que estar dispostos a se aplicarem nos aspectos, teóricos, metodológicos e operacionais que a proposta do Ensino Superior os traz ao ingressar seja em nível de graduação, pós-graduação, mestrado ou doutorado. 
Portanto, este trabalho finda em demonstrar como a associação dos saberes e competências do docente com os métodos e práticas pedagógicas podem tornar a disciplina Metodologia de Pesquisa numa disciplina atraente aos discentes do Ensino Superior visto que essa disciplina faz com que o discente desperte suas habilidades do pensamento crítico e desenvolva suas competências na organização destes pensamentos. Isso comprova que o discente bem orientado consegue colocar de forma organizada e culta suas ideias no papel, cooperando para exercitar o bom senso e a enfrentar maiores desafios da vida.

\section{Considerações Finais}

Devemos considerar que a docência no Ensino Superior é uma atividade realizada como mediação e orientação na construção de conhecimentos e na formação pessoal e profissional. Nela, os sujeitos envolvidos nesse processo possuem diferenças baseadas com a realidade e situação que se encontram. Assim, docente e discente necessitam construir juntos novos saberes e possibilidades através de uma visão crítica dos conteúdos estudados.

Ao docente de Ensino Superior é necessário manter um olhar a respeito da necessidade do aprendizado diário, a partir da preparação da sua aula, da avaliação da mesma, bem como, no confronto e construção de saberes em conjunto com seus alunos, utilizando sempre de práticas e métodos pedagógicas que proporcionam a aula mais atrativa a ambos.

Ao estudar a respeito da docência no Ensino Superior, torna-se necessário relacionar a importância da pesquisa na formação do professor, desde a construção do conhecimento científico e sua aplicabilidade prática, assim como pesquisar a própria prática docente, demonstrando preocupação no sentido de realizar uma reflexão sobre o cotidiano da aula e, por consequência, nas possibilidades de melhoria no processo. Por fim, demonstrando o quanto os métodos e práticas pedagógicas bem desenvolvidos durante o processo de ensino aprendizagem, contribuem para que a disciplina de metodologia de pesquisa se torne atrativa aos alunos do Ensino Superior, visto que sua carreira nos estudos depende de um leque de informações e conhecimentos que essa disciplina produz através dos sabedores e competências docente.

A perspectiva de futuros trabalhos sobre a mobilização de conhecimento, saberes e habilidades está na continuidade da pesquisa ser realizada com dados empíricos, visto que a mesma se trata de uma reflexão bibliográfica, podendo ser considerada como fator limitante ao aprofundamento de dados.

\section{Referências}

ABNT. (2019). Fundação Brasileira de Normas Técnicas. http://www.abnt.org.br/abnt/conheca-a-abnt.

Almeida, M. E. B. (2000). Informática e formação de professores. Ministério da Educação, Seed.

Bireaud, A. (1995). Novas práticas pedagógicas no ensino superior. Porto Editora.

Bogdan, R. C.\& Birten, S. K. (1982). Qualitative research for education; an introduction for to theory and methods. Boston, Allyn and Bacon, pp. 27-30.

Brasil. (1996). Lei de Diretrizes e Bases da Educação Nacional. Portal da Legislação: Leis Ordinárias. In: http://www.planalto.gov.br/c civil_03/leis/19394.htm

Carvalho, M. G., Bastos, J. A. de S. L. \& Kruger, E. L. de A. (2000). Apropriação do conhecimento tecnológico. CEEFET-PR.

Carvalho, J. A. de, Carvalho, M. P. de, Barreto, N. A. M. \& Alves, F. A. (2010). Andragogia: Considerações sobre a Aprendizagem do Adulto. Ensino, Saude E Ambiente, 3(1), 78-90, https://doi.org/10.22409/resa2010.v3i1.a21105

Cerutti, E. \& Giraffa, L. M. M. (2015). Uma nova juventude chegou à universidade: e agora professor? CRV.

Cortella, M. S. (2016). Educação, escola e docência, novos tempos, novas atitudes. ABDR.

Deaquino, T. C. E. (2007). Como Aprender: Andragogia e as habilidades de aprendizagem. Pearson Prentice Hall.

Demo, P. (2006). Pesquisa: princípio científico e educativo. (12a ed.) Cortez.

Domingues, G. S. (2016). Andragogia de Jesus - A metodologia de Ensino que Transformou o Processo Educativo. (2a ed.), A.D. Santos.

Fernandes, J. C. L. \& Silva, A. T. P. (2017). Práticas Pedagógicas para o Ensino Superior. Revista de Pós-graduação Multidisciplinar, 1(2), 363-372 
Freire, P. (1997). Pedagogia da Autonomia: Saberes necessários à prática educativa. Paz e Terra.

Galliano, A. G. (1986). O método científico: teoria e prática. Harbra.

Hamze, A. (2019). Andragogia e a arte de ensinar aos adultos. https://educador.brasilescola.uol.com.br/trabalho-docente/andragogia.htm

Kenski, V. M. (2012). Educação e Tecnologias: o novo ritmo da informação. Editora Papirus.

Kenski, V. M. O papel do professor na sociedade digital. In: Castro, A. D. de, Carvalho, A. M. P. de (org.). (2001). Ensinar a ensinar: didática para a escola fundamental e média. Pioneira Thompson Learning.

Libâneo, J. B. (2001). Introdução à vida intelectual. Loyola.

Lobo, A. S. M. \& Maia, L.C. G. (2015). O uso das TICs como ferramenta de ensino-aprendizagem no Ensino Superior. Caderno de Geografia, 25(44), 16-26, $10.5752 /$ p.2318-2962.2015v25n.44p.16

Malheiros, B. T. (2011). Metodologia da Pesquisa em Educação. LTC.

Martins, P. B. \& Curi, E. Collaborative groups: a reflective look for the professional development of mathematics teachers. Research, Society and Development, 7(1), e771133, 2018. 10.17648/rsd-v7i1.98. https://rsdjournal.org/index.php/rsd/article/view/166.

Masetto, M. T. (2012). Competência pedagógica do professor universitário. (2a ed.), Summus.

Menezes, E. T. de. (2018). Para além dos usos das tecnologias digitais: um estudo acerca da formação e atuação docente no ensino superior de doutorandos do Programa de Pós-Graduação em Educação da USP 2018. Tese Doutorado em Formação, Currículo e Práticas Pedagógicas - Faculdade de Educação, Universidade de São Paulo.

Mellouki, M. \& Gauthier, C. (2004). O professor e seu mandato de mediador, herdeiro, intérprete e crítico. Educ. Soc., 25, (87), 537-571, https://doi.org/10.1590/S0101-73302004000200011

Silva, E. A. (2013). As metodologias qualitativas de investigação nas ciências sociais. Revista Angolana de Sociologia, $77-99$.

Slomski, V. (2007). Saberes e competências do professor universitário: contribuições para o estudo da prática pedagógica do professor de Ciências Contábeis do Brasil. Revista de Contabilidade e Organizações, 1(1), 89-105, https://doi.org/10.11606/rco.v1i1.34699

Vasconcelos, M. L. Docência e autoridade no ensino superior: uma introdução ao debate. In: Teodoro, A. \& Vasconcelos, M. L. (orgs). (2005). Ensinar e aprender no ensino superior: por uma epistemologia da curiosidade na formação universitária. (2a ed.), Mackenzie/Cortez.

Valente, J. A. (2005). A Espiral da Espiral de Aprendizagem: o processo de compreensão do papel das tecnologias de informação e comunicação na educação. Tese (Livre Docência) Departamento de Multimeios, Mídia e Comunicação, Instituto de Artes (IA).

Vargas, S. A. (2017). A docência no Ensino Superior em Ciências Contábeis: Reflexões sobre os saberes à prática educativa. Dissertação (Mestrado em Educação), Programa de Pós-Graduação Stricto Sensu em Educação, Universidade Regional Integrada do Alto Uruguai e das Missões, Frederico Westphalen.

Tardif, M. (2002). Saberes docentes e formação profissional. (4a ed.), Vozes.

Tardif, M. (2014). Saberes docentes e formação profissional. (17a ed.), Vozes.

Tartuce, T. J. A. (2006). Métodos de pesquisa. Fortaleza. UNICE Ensino Superior.

Tavares, S. T. de P. \& Gomes, S. A. R. (2018). Educação e aprendizagem no século XXI: o papel do professor e do aluno frente aos impactos das tecnologias da informação e da comunicação (tic) na educação. Evidência, 14(15), 59-71, 10.29327/evidencia.v14.i15.a4

Teixeira, E. (2010). As três metodologias: acadêmica, da ciência e da pesquisa. (7a ed.), Vozes.

Pimenta, S. \& Anastasiou, L.das G. C. (2010). Docência no Ensino Superior. (4a ed.), Cortez.

Pinto, A. V. (2007). Sete Lições Sobre Educação de Adultos. (15a ed.), Cortez Editora.

Praça, F. S. G. (2015). Metodologia da Pesquisa Científica: Organização Estrutural e os Desafios para Redigir o trabalho de Conclusão. Revista Eletrônica "Diálogos Acadêmicos", 8 (1), 72-87.

Prodanov, C. C. \& Freitas, E. C. (2013). Metodologia do trabalho científico [recurso eletrônico] métodos e técnicas da pesquisa e do trabalho acadêmico. Feevale.

Zabalza, M. A. (2004). O ensino universitário: seu cenário e seus protagonistas. Artmed. 